\title{
Stuart Hall: Marx, Gramsci y la cuestión de la crisis
}

\section{Jorge Daniel Vásquez}

\section{Resumen}

El objetivo de este artículo es delinear dos perspectivas para el análisis del neoliberalismo a partir del pensamiento de Stuart Hall. En este sentido, se reconstruye la aproximación de este autor con el pensamiento de Marx y Gramsci, así como su análisis de la crisis de la sociedad británica en tanto fenómeno cultural, social y político en su obra Policing the crisis (1978) y The hard road to renewal (1988). Este artículo complejiza la lectura tanto del "momento althusseriano" como de la "mirada gramsciana" de Stuart Hall para comprender los principales dilemas teóricos de años setenta y ochenta. Finalmente, se observa el lugar del racismo y de la producción de sentido común como pilares del análisis de la crisis de hegemonía.

Palabras clave: neoliberalismo, crisis, racismo, hegemonía.

* Pontificia Universidad Católica del Ecuador, Quito, Ecuador. 


\section{Stuart Hall: Marx, Gramsci and the crisis issue}

\section{Abstract}

The objective of this article is to delineate two perspectives for the analysis of neoliberalism based on Stuart Hall's thought. In this regard, the article not only addresses Hall's approach to Marx and Gramsci's thought, but also Hall's analysis on the crisis of British society, while a cultural, social, and political phenomenon as it appears in his books Policing the crisis (1978) and The hard road to renewal (1988). Therefore, this article complexifies Stuart Hall's "Althusserian moment" as well as his "Gramscian gaze" for understanding the main theoretical dilemmas of the 1970s and 1980s. Finally, this paper observes the place of racism and the production of common sense as pillars of the analysis of the hegemony crisis. ${ }^{1}$

Keywords: neoliberalism, crisis, racism, hegemony.

En la lucha por las ideas, la batalla por los corazones y las mentes que la derecha ha venido conduciendo con tan considerable efecto, las malas ideas sólo pueden ser desplazadas por ideas mejores y más adecuadas.

Stuart Hall, The hard road to renewal (1988, p. 73)²

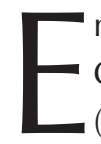

n su artículo "Apuntes sobre el método de Stuart Hall. Althusser, Gramsci y la cuestión de la raza", el intelectual italiano Miguel Mellino (2018), reconstruye la originalidad de los argumentos derivados tanto del "momento althusseriano" así como "de la mirada gramsciana" de Stuart Hall sobre la coyuntura intelectual y política de los años setenta y ochenta. Tal reconstrucción es fundamental para comprender cómo, a partir de la confrontación con los principales dilemas teóricos de una época, se deriva la construcción de un método para el análisis de las crisis de hegemonía.

\footnotetext{
1 Agradezco a Liliam Fiallo, Laura García Corredor y Sut Jhally por sus comentarios a la versión previa de este artículo.

${ }^{2}$ En el original: "In the struggle for ideas, the battle for hearts and minds which the right has been conducting with such considerable effect, bad ideas can only be displaced by better, more appropriate ones." (Hall, 1988, p. 73). A partir de aquí, las traducciones al español de las citas de Stuart Hall son realizadas por el autor de este artículo.
} 
Si bien para Mellino (2018, p. 92) "no es importante concentrarse tanto en estos [los] aspectos objetivos, por así llamarlos, de la crisis, sino en la forma en la que era percibida por Stuart Hall", ${ }^{3}$ sí resulta necesario establecer los principios analíticos que sostienen la relevancia del marco crítico construido por Hall. Dos de los aportes fundamentales del artículo de Mellino radican tanto en ubicar a Hall dentro del desarrollo del posmarxismo, el pensamiento anticolonial, y el análisis "materialista" poscolonial (Mellino, 2018, p. 100-102) como en señalar la manera en que logró integrar elementos del althusserianismo y a la vez trascender sus limitaciones (Mellino, 2018, p. 102-103).

Mi propósito en este artículo es ofrecer una perspectiva que no sólo complemente, sino que profundice la reconstrucción que realiza Mellino. Así, me permito señalar dos anclajes fundamentales del pensamiento de Stuart Hall para el análisis del neoliberalismo en las condiciones que hacen posible su emergencia en cuanto propuesta societal, así como proyecto político. Con este fin, en la primera parte se plantean los aspectos de Marx que Hall consideró fundamentales para su crítica y la formulación acerca de la "primera instancia" de la determinación de lo histórico-social. A continuación, se identifican los elementos gramscianos en su crítica a la "certeza teórica" que se atribuían los marxismos de su época. Las dos últimas secciones responden a dos principios para el análisis de la relación entre crisis y neoliberalismo a partir del pensamiento de Stuart Hall: 1) el lugar del racismo en las condiciones de transición, y 2) la producción de sentido común como condición para la construcción de hegemonía.

Así, además de los puntos complementarios al texto de Mellino, es importante señalar que este artículo parte de un criterio discordante. Mellino (2018, p.100) considera que

si se quiere entender el sentido de la traducción gramsciana de Hall, es necesario buscar en otro lado, específicamente, en sus textos más densos desde el punto

${ }^{3}$ Mellino, siguiendo el lenguaje de Hall, nombra la crisis como "la "crisis del consenso posbélico', es decir, de esa específica formación social y política que había gobernado la construcción de la así llamada "sociedad del bienestar" en Gran Bretaña" (Mellino, 2018, p. 93). 
de vista teórico como los ya citados "Marx's notes on method: a reading of the 1857 introduction" (1973); "Rethinking the 'Base and Superstructure' metaphor" (1977), pero sobre todo en los escritos sobre raza y racismo, en especial en "Race, articulation and societies structured in dominance" (1980b), "The problem of ideology: Marxism without guarantees" (1986a), "Gramsci's relevance for the study of race and ethnicity (1986b). ${ }^{4}$

Esta afirmación se presenta a partir de la atribución implícita de un carácter "menos denso" a los textos en los que Hall utiliza los conceptos gramscianos para el análisis del fenómeno concreto del Thatcherismo: The hard road to renewal. Thatcherism and the crisis of the left (1988a), y The toad in the garden': Thatcherism among theorists (1988b). Según Mellino (2018, p. 100), "lo que tenemos en estos casos es un uso sobre todo "didáctico" y "divulgativo", por así decirlo, de algunos conceptos gramscianos empleados en el análisis de un objeto específico, [...], más que una confrontación o un análisis teórico-político-epistemológico del archivo gramsciano". Sin embargo, ¿no es en este análisis de la situación concreta precisamente el lugar en el que el método demuestra sus alcances y limitaciones? ¿no es pues, el análisis de las condiciones del suceso histórico el espacio en que la crítica se constituye como tal? A diferencia de Mellino, considero que estos textos "didácticos" no sólo presentan efectivamente elementos teóricopolíticos del pensamiento de Stuart Hall, sino que, a la vez, constituyen un referente indispensable para acercarse a la complejidad de su método.

Así, en las primeras dos secciones de este artículo retomo algunos de los textos "más densos" también trabajados por Mellino, incluyendo además las lecciones del seminario dictado en la Universidad de Illinois at UrbanaChampaign en 1983, ${ }^{5}$ así como el artículo Signification, representation, ideology: Althusser and the post-structuralist debates (1985).

${ }^{4}$ El resaltado en "más densos" es mío. En los trabajos publicados en 1986 que aparecen como 1986a y 1986b, el literal que sigue al año corresponde al orden de citación en el texto original de Mellino.

${ }^{5}$ Estas lecciones fueron publicadas como libro en 2016 con el título Cultural studies 1983. A theoretical history (Hall, 2016). 
Si bien Mellino se detiene en varios pasajes de la obra Resistance through rituals. Youth subcultures in post-war Britain (Hall; Jefferson, 1976) para referirse al análisis de la crisis, mi opción en la tercera sección de este artículo es detenerme en la obra Policing the crisis. Mugging, the State and law \& order (Hall et al., 2013), cuya segunda edición apareció 35 años después de la original. Mi interés es considerar Policing the crisis en la medida que establece una perspectiva de análisis de la cuestión racial en el neoliberalismo. Con respecto a este libro, Hall declaró, en su última entrevista, que

Policing the crisis fue particularmente importante porque decía que se puede abordar una coyuntura desde varios puntos de vista diferentes, y que la raza es una excelente manera de entrar en los efectos ocultos e inconscientes, así como en los efectos conscientes y explícitamente discriminatorios, que tiene la raza en la sociedad (Jhally, 2016, p. 333). ${ }^{6}$

Finalmente, en la cuarta sección de este artículo se considera una segunda perspectiva analítica que complementa la reconstrucción del método realizada por Mellino, precisamente a partir de la lectura de The hard road to renewal. Thatcherism and the crisis of the left (1988a), así como The toad in the garden: Thatcherism among theorists (1988b) a la luz de los puntos expuestos en las secciones anteriores.

\section{"The first instance": Hall, lector de Marx}

En El Capital, el análisis de los mecanismos de las sociedades modernas capitalistas tiene como punto de partida la consideración de la mercancía en su doble naturaleza (Marx [1867] 1946, p. 3-47). No es casual que sea la mercancía el objeto de pensamiento con el que Marx inicia su obra de tres volúmenes, pues ésta se enmarca en la producción crítica del conocimiento, es decir, en el propósito de comprender las condiciones que hacen posible el

${ }^{6}$ En el original: "Policing the crisis was particularly important because it said you can get into a conjuncture from several different vantage points, and race is an excellent way for getting into the hidden and unconscious - as well as the conscious and explicitly discriminatory effects of race on the society." (Jhally, 2016, p. 333). 
funcionamiento de todo un sistema. El carácter concreto y a la vez abstracto de la mercancía da cuenta de esas condiciones materiales y al mismo tiempo ideológicas imbricadas en las relaciones sociales de producción.

Stuart Hall retomó estos elementos presentes en el proyecto de Marx, lo que implicó una lectura de su producción teórica (especialmente La Ideología Alemana, El Dieciocho Brumario de Luis Bonaparte, Contribución a una Crítica de la Economía Política, Grundrisse, El Capital), y de la correspondencia con Friedrich Engels. Ello le permitió sostener una discusión con el marxismo (estructuralista) de la época, especialmente con Louis Althusser.

Uno de los lugares en los que el pensamiento de Hall expresa su rigurosa lectura y crítica de Marx y el marxismo, se encuentra en la discusión de la metáfora base-superestructura. Hall $(1977 ;$ 2016) señala que la metáfora base-superestructura no tiene una única acepción en la obra de Marx pues, para el propio Marx, esta metáfora puede referirse a la determinación de las circunstancias materiales (la base) sobre las áreas de la superestructura (las ideologías), así como a la naturaleza de las relaciones existentes entre los distintos niveles (nivel económico en la base y nivel ideológico o superestructural) de una formación social.

Marx también utiliza esta metáfora para referirse al conjunto complejo de la sociedad como una totalidad (el ensamblaje de lo económico con lo ideológico). No obstante, en todos los casos, Hall reconoce que la metáfora apunta a dar un paso más allá del idealismo hegeliano (a provocar su "inversión" en términos althusserianos), planteando que el desarrollo de la historia debe explicarse desde las prácticas materiales reales y las circunstancias que las hacen posibles.

De la lectura sobre el problema de la ideología (en La ideología alemana), así como la de las circunstancias históricas que provocaron el desenlace bonapartista en Francia (en El dieciocho brumario), se desprende la necesaria discusión del modelo base-superestructura a partir del problema de la determinación. El planteamiento realizado en La ideología alemana: "las ideas de la clase dominante son en cada época las ideas dominantes, es decir, la clase que es la fuerza material dominante es a la vez su fuerza intelectual 
dominante" (Marx; Engels, [1845] 1970, p. 64) dio pie a lecturas "garantistas" de la historia, asumiendo que, "en última instancia", es la economía (las relaciones económicas en la base de la estructura social) la que determina el curso de los acontecimientos históricos. El mismo Engels se refiere a este determinismo, en el momento en que, si bien reconoce que tanto la cultura como la religión y la ley interactúan en la concepción materialista de la historia, no es menos cierto que "es la interacción entre todos estos factores y en medio de una interminable multitud de eventualidades [...] que la tendencia económica finalmente se afirma como algo inevitable" (Engels, [1890] 2002, p. 34-35).

Stuart Hall lleva esta discusión a una dimensión que permite pensar desde el marxismo "sin garantías". ${ }^{7} \mathrm{Si}$, en el modelo base-superestructura, la base es la parte dominante de la relación, el tiempo presente se convierte en la simple espera del cumplimiento de una profecía: en última instancia, el curso de la historia será determinado por la economía. Tal principio constituyó el punto de atención de Hall para leer a Marx sin caer en el juego del determinismo. Así, en su problematización del modelo base-superestructura, Hall (1996b) si bien se aparta del determinismo, no abandona la pregunta por la determinación abriendo una vía que implica reconocer la necesaria articulación de diferentes instancias en cada acontecimiento de la historia.

El argumento se basa en lo siguiente: si las diversas maneras en las que se generan formas de organización social, a través de las cuales los seres humanos intervienen en la naturaleza, se dan en el marco de condiciones históricas específicas, éstas últimas constituyen precisamente

\footnotetext{
7 Mellino considera que los fundamentos para marxismo "sin garantías" se inscriben en el "momento althusseriano" de Hall. Afirma: "la influencia del 'momento althusseriano' en el desarrollo de la problemática de Hall puede ser deducida de otros presupuestos. Se puede pensar, por ejemplo, en una expresión como without guarantees, un enunciado epistemológico tan amado por Hall (y profundamente asociado a su perspectiva tanto sobre el objetivo del 'trabajo teórico' como sobre el de las identidades culturales), pero que es, en realidad, una enunciación epistemológica clave del tipo de marxismo sobre el cual trabajaba Althusser" (Mellino, 2018, p. 98). Más que señalar los puntos de contacto y separación (o el paso de la cercanía al distanciamiento) de Hall con Althusser, me interesa seguir la pista de lo que Hall logró hacer con el marco de pensamiento althusseriano para su propio proyecto crítico.
} 
the first instance (i.e. la primera instancia de determinación), de la propia determinación económica. Esta "primera instancia" de la determinación es pues el contexto, el conjunto de condiciones históricas en las que las relaciones de producción y el desarrollo de las fuerzas productivas tienen lugar. Tal conjunto de condiciones históricas conforma una coyuntura, una particular configuración de la relación entre base y superestructura que debe analizarse más allá de cualquier garantía: una forma de relación que mantiene vigente la necesidad de analizar los acontecimientos dentro de sus condiciones de existencia.

The first instance es el terreno en el que la experiencia, el devenir, tiene lugar. Así, desde el pensamiento de Hall, la expresión de El dieciocho brumario: "los hombres hacen su propia historia, pero no lo hacen a su libre arbitrio, bajo circunstancias elegidas por ellos mismos, sino bajo aquellas circunstancias con que se encuentran directamente, que existen y les han sido legadas por el pasado" (Marx [1852] 1969, p. 99) recobra una potencialidad para el pensamiento marxista pues son las condiciones que no elegimos, las que configuran the first instance. Hall mismo se referirá al Prefacio de la contribución a la crítica de la economía política como un texto más cercano a la "ilusión de la garantía" (eso que Hall llama the theoretical certainty), mientras, en El dieciocho brumario, Marx aparece analizando la coyuntura que hizo posible el ascenso de Louis Bonaparte cuando, en su lugar, parecían darse las condiciones para un ascenso del proletariado. En este sentido, Hall verá en El dieciocho brumario un ejemplo claro del análisis de "la efectividad y especificidad de la instancia política en relación a la económica"8 (Hall, 1977, p. 55).

Así, la discusión del modelo base-superestructura lleva a Hall a proponer una forma de comprender la determinación, lo que lo sitúa en el mismo nivel de intención de Marx: pensar las condiciones de posibilidad, los términos en los que se asignan limitaciones al aspecto económico (la "determinación por lo económico en la primera instancia") (Hall, 1996b,

${ }^{8}$ En el original: "the effectivity and specificity of the political instance in relation to the economic" (Hall 1977, p. 55). 
p. 45). De tal modo, la determinación que proporciona lo ideológico por lo económico no es pues de una sola vía sino de determinación mutua.

Con su desarrollo sobre the first instance, Hall es, como Marx, un pensador de la totalidad. Esto no significa que realice una reducción del todo a un particular elemento explicativo, sino que, precisamente, entra en conexión con los trabajos iniciales de Marx desde la comprensión de diferentes prácticas, no sólo dentro de las condiciones económicas, sino también dentro de aquello que lo económico no puede proveer: los contenidos del pensamiento de una clase social en un momento dado, así como las categorías que serán usadas por las clases sociales con mayor duración en el tiempo. ${ }^{9}$

\section{Contra "the theoretical certainty": Hall y Gramsci}

La lectura de Gramsci y Althusser constituyeron una contribución esencial al método de Stuart Hall. Sobre el primero, se podría decir que Hall integra su aparato conceptual y que la perspectiva de los Estudios Culturales como proyecto teórico y político tiene que ver con la manera en que Gramsci asume la tarea del pensamiento y la praxis. Por otro lado, Hall habría recorrido la obra de Althusser en varios de sus ensayos (Hall 1977; 1985; 1996a; 2016), siendo el mayor aporte de Althusser a este método el debate sobre la determinación y la sobredeterminación - incluido en Pour Marx (Althusser, 2005) -, que llevó a Hall a plantear una postura propia en torno a este problema. Así, Hall propuso la "articulación" de las diferencias como un trabajo político a partir del reconocimiento de la "no necesaria correspondencia" entre los niveles de una formación social. En los párrafos siguientes presentaré en detalle estas contribuciones desde la manera en que tanto Gramsci como Althusser, fueron tratados en la obra de Stuart Hall.

${ }^{9}$ Creo que esto, además de estar manifiesto en los textos donde Hall analiza el problema base-superestructura $(1977 ; 2016$; 1996b), se expresa también en el objeto complejo de la mercancía (punto de partida de El Capital), en el que confluyen las distintas instancias de determinación que atraviesan el proceso de producción material y simbólico de principio a fin. 
En su análisis de la situación de Inglaterra en la década de 1980, Hall asume el sistema de pensamiento construido por Gramsci (que incluye conceptos como "sentido común", "hegemonía", "relaciones de fuerza", "bloque histórico") con el propósito de renovar la idea marxista de que la política no consiste en la erradicación del conflicto, sino en la manera de determinar las posibilidades existentes en una particular configuración de la lucha política (Gramsci 1971, p. 57-58).

Así, en "Gramsci and us", capítulo de su libro dedicado al análisis del Thatcherismo, Hall sostiene: "no digo, de ninguna manera sencilla, que Gramsci 'tiene las respuestas' o que 'posee la clave' para nuestros problemas actuales. Lo que sí creo es que debemos 'pensar' nuestros problemas en un sentido gramsciano - lo cual es distinto" (Hall 1988a, p. 161). ${ }^{10}$ En esta cita, pero también a lo largo de todo el capítulo, hay una clara identificación entre el cuestionamiento de Gramsci acerca del fracaso de la revolución en Italia, y la "lección jamás aprendida" de la izquierda en medio de la situación que Gran Bretaña experimentaba con el gobierno de Margaret Thatcher.

Gramsci cuestionó el modelo base-superestructura desde su "falta de revolución", tomando como objeto de análisis el curso - diametralmente opuesto - que toma la historia, una vez que haya fracasado un intento revolucionario. Desde Gramsci, Hall veía el curso que Gran Bretaña tomaba instalando un nuevo sentido común en el pueblo británico, entendía que la disputa debía darse en el terreno de la cultura política, y denunciaba cómo la transformación del Estado impulsada por Thatcher buscaba atravesar la vida cotidiana de los sujetos. En este sentido, Hall encontró que el terreno político se define desde la diversificación de las luchas sociales, y no desde "los viejos ritmos de la 'lucha de clases'" (Hall, 1988a, p. 168). Eran precisamente los términos de la lucha lo que se había transformado sin que la izquierda británica lo percibiera. Esta vez, desde Gramsci, Hall

${ }^{10}$ En el original: "I do not claim that, in any simple way, Gramsci 'has the answers' or 'holds the key' to our present troubles. I do believe that we must 'think' our problems in a Gramscian way - which is different." (Hall 1988a, p. 161). 
volvió a cuestionar el marxismo que pretende reposar en "la certeza teórica" (the theoretical certainty).

Al igual que en los escritos de Antonio Gramsci, el concepto de hegemonía tiene un lugar central para Stuart Hall. "Hegemonía" es un término inicialmente formulado por Lenin, pero que fue expuesto por Gramsci en su análisis sobre la revolución comunista entre 1920 y 1930 en Europa de Occidente, como una entrada a la pregunta por la derrota de las fuerzas revolucionarias, el retroceso del movimiento comunista, y el empuje de fuerzas sociales que condujeron al fascismo.

No obstante, Hall Ileva a Gramsci no sólo al análisis del neoliberalismo (Hall, 1988a), sino al análisis de la raza y la etnicidad (Hall, 1996a) desde una recuperación de Marx que, lejos de esquemas positivistas y economicistas, consigue mantener en una perspectiva materialista compleja. Con relación a esto último, Hall (1996a, p. 418-420) busca destacar la manera en que Gramsci realiza una crítica del pensamiento "científico" de su época (i.e., desde el positivismo al economicismo, pasando por el "materialismo vulgar" de Bukharin) y la relación de éste con la concepción idealista de la historia, que aspira a que la transformación social radique en la transformación de la conciencia individual. El señalamiento de los límites de tal planteamiento idealista pasa por reconocer, para Antonio Gramsci, que la centralidad del pensamiento y la formación de la conciencia está en la praxis, en tanto esta categoría permite expresar que la acción de los seres humanos se da en el marco de "formaciones sociales" en la cuales lo económico, político e ideológico se articulan (Hall, 1996a, p. 121).

Sabemos por Gramsci que la burguesía opera desde la acumulación de fuerzas mediante su rol dominante en la economía y en la producción intelectual. Tal operación, de la cual el Estado sería "el último golpe" (por representar la llegada al monopolio de la coacción), se mantiene debido a la acumulación constante de las formas de producir la filosofía, la pedagogía, la valoración de las prácticas sociales. Precisamente, para Gramsci, el análisis de la captación del sentido de unas determinadas circunstancias históricas (i.e. de lo que Hall denomina the first instance) es vital para comprender 
la configuración de la "hegemonía". "Hegemonía" se refiere precisamente a la manera cómo se articulan las heterogeneidades y sus diferencias en diversos campos.

En la concepción de la hegemonía podemos ver en funcionamiento la concepción de "no necesaria correspondencia" propuesta por Hall, pues la articulación no es la simple conexión de los niveles de la formación social, sino precisamente la manera en que tales niveles se conectan.

No obstante, no sólo el aporte de Gramsci fue crucial al desarrollo del proyecto de Estudios Culturales. El aporte de Althusser fue precisamente señalar que los elementos de la formación social no "se reflejan" unos a otros (como en el esquema de una base reflejada en la superestructura) sino que tales elementos se "sobredeterminan", afectándose mutuamente - "[...] lo que ya en sí mismo constituye una inmensa revolución teórica" (Hall 1985, p. 97). ${ }^{11}$ Para Hall, este es el punto en que el pensamiento de Gramsci y los primeros trabajos de Althusser contribuyeron al método de los Estudios Culturales en la pregunta por la manera en que los distintos niveles se conectan.

Los niveles se conectan en una "no necesaria correspondencia", punto desde el cual Hall (1985) se aparta de dos visiones reduccionistas. En primer lugar, se aparta de aquella que sostiene la "necesaria correspondencia" entre un plano o nivel de cierta formación social con otro plano o nivel dentro de la misma formación social o en otra diferente. En segundo lugar, se aparta del enfoque de una "necesaria no correspondencia" entre las características del fenómeno (digamos la identidad) con respecto a la clase social y con respecto a la ideología. De este modo, al igual que Gramsci, Hall señala el peligro del reduccionismo de clase, pero sin que esto lo lleve a rechazar la cuestión de clase. De lo que se trata es de comprender cómo se da tal articulación.

A partir de aquí, se puede conceptualizar la hegemonía como una articulación entre los niveles de la formación social que, dadas ciertas condiciones, se expresa en el consenso desde el cual un sector de la sociedad

${ }^{11}$ En el original: "[...] that in itself constitutes an immense theoretical revolution." (Hall 1985, p. 97). 
extiende su visión particular del mundo, aunque de modo contradictorio, al terreno del sentido común, "el terreno de las concepciones y categorías sobre las cuales se forma realmente la conciencia práctica de las masas" (Hall 1996a, p. 431). ${ }^{12}$ Corresponde entonces analizar (a nivel teórico) la hegemonía como una articulación que permite ejercer el poder desde el consenso, y, a la vez, construir (a nivel político-teórico) una nueva hegemonía. Para Hall es esta comprensión del pensamiento como praxis (que articula lo teórico y lo político) la base fundamental del trabajo del intelectual orgánico.

Finalmente, se podría señalar que el pensamiento de Gramsci contribuye a los Estudios Culturales en tanto ubica el estudio sobre la raza y la etnicidad por fuera de las formas de "la tradición" como recurso premoderno para otorgar identidad. Si por identidad entendemos el sentido del conjunto de acepciones históricas que forman nuestros esquemas interpretativos del mundo, la tradición comporta un pasado que es fuente de normas y creencias que se traducen en formas de legitimación. En sentido gramsciano, la tradición legitima el ejercicio del poder y la autoridad (mediante características legales o carismáticas).

El pensamiento de Gramsci, señala Hall, implica considerar la especificidad histórica en la que se dan las prácticas de racismo, así como las condiciones nacionales y regionales para su desarrollo. Quizás, el tema más sensible tiene que ver con la difícil articulación entre las condiciones de raza y clase. Sin ser nada fácil, el punto de partida de Gramsci es pensar la articulación entre ambas dentro de las "cualidades particularmente específicas de las formaciones de clase en cualquier sociedad históricamente específica" (Hall, 1996a, p. 436) y a la vez reconocer el carácter no homogéneo del sujeto; pensar la articulación de sujetos que son víctimas de mistificaciones producto de la ideología; y contar con el trabajo intelectual que también es trabajo político. Sugiero que es éste el aspecto en el que Stuart Hall es plenamente gramsciano, al asumir la

${ }^{12}$ En el orginal: "the terrain of conceptions and categories on which the practical consciousness of the masses of people is actually formed." (Hall, 1996a, p. 431). 
tarea intelectual orgánicamente, consciente de su carácter político (toda teoría de la cultura implica una teoría del poder), y con la exigencia de "comprender mejor que los intelectuales tradicionales" (Hall, 1996a, p. 433) a fin producir articulaciones que faciliten las transiciones entre niveles de la formación social.

\section{Análisis de la crisis (I): el lugar del racismo en la transición al neoliberalismo}

El concepto de raza es central en toda la obra de Stuart Hall. Sin embargo, es fundamental en el análisis de la crisis como fenómeno social, especialmente en el trabajo seminal de los Estudios Culturales, Policing the crisis (Hall; Critcher; Jefferson; Clarke; Roberts, 2013). Tal obra es resultado del esfuerzo de los autores por comprender un momento de transición entre dos coyunturas. En primer lugar, se encuentra la coyuntura del Estado de Bienestar construido por la social democracia. Esta, como propuesta política, intentó resolver la contradicción entre capital y trabajo a través de una redistribución del crecimiento económico. En los años 1960, la economía inglesa empezó una recesión que significó la desestabilización de las garantías provistas por el Estado (Jhally, 2016; Mellino, 2018). A esto se puede añadir que en esa década se instauró la propagación de un discurso que caracteriza al Estado, y su rol protagónico en la economía, como una "forma de intromisión" en la vida de las personas. Tal discurso tuvo como finalidad contraponer el modelo social demócrata de sentido keynesiano (Hall, 1988b).

El trabajo realizado por Hall y colegas (2013) es un análisis de la crisis contemporánea y a la vez es "una historia del presente". Una perspectiva interesante de temporalidad caracteriza a Policing the crisis: el análisis de la situación concreta de la sociedad inglesa en los años 1970, ubicada en el medio de un cambio de modelo económico y también del desbalance de valores que habían mantenido cohesionada a la sociedad inglesa desde los tiempos de su propia constitución imperial/imperialista. La combinación de 
estos niveles en el análisis (crisis política y crisis de identidad) es lo que hizo posible que este libro diera cuenta de las condiciones para el surgimiento del Thatcherismo (Jhally, 2016).

Tal como declara el propio Hall (Jhally, 2016, p. 332-333), Policing the crisis no sólo fue el resultado de una escritura grupal, sino que posicionó un método de análisis de la coyuntura. Si bien no hay "aplicación" posible de Policing the crisis, sí hay una posibilidad de adecuación de su método a la coyuntura actual.

No obstante, la clave de entrada para tal análisis es el fenómeno del mugging (i.e. asalto), el cual funcionó como punto de cohesión para comprender la crisis política y moral que estaba detrás de lo que se pretendió construir como una crime crisis. Para situar la llamada "crisis de crimen" o "crisis de seguridad", los autores traen a colación el episodio acerca de las desproporcionadas sentencias a tres jóvenes negros en los tribunales de justicia por mugging (Hall et al. 2013, p. xii-xiii). Para esos autores tales "aleccionadoras" sentencias expresaban una desintegración del orden político-moral de la sociedad, de tal modo que la crisis del crimen no es sino la crisis en cuanto desestabilización de certezas económicas, políticas y culturales.

La revisión de las estadísticas sobre el crimen reveló que el término mugging no era utilizado para la tipificación de ningún delito (lo que sí existía era la expresión "robo con violencia"), de tal modo que mugging fue un término acuñado por los medios de comunicación que, a su vez, generaba las condiciones para la propagación mediática de la "dureza" con la que los "criminales" serían tratados por la justicia inglesa (Hall et al., 2013, p. 17). De este modo, Policing the crisis, revela la manera en que, aún cuando no exista una evidencia concreta que permita hablar del ascenso del crimen (de hecho, el número de delitos en ese momento iba en disminución), el proceso de producción de diferentes etiquetas permite una articulación que hace sentido de la situación pues "ellas [las etiquetas] no solo colocan e identifican esos eventos, sino que asignan eventos a un 
contexto. De ahí que, es probable que el uso de la etiqueta movilice todo un contexto referencial [...]" (Hall et al. 2013, p. 23). ${ }^{13}$

La creación del término mugging permitió el etiquetamiento de la crisis. Sin embargo, no puede ser absolutamente casual que sea el término mugging y no otro, pues, para los autores, mugging es producto de una importación de etiquetas (an export-import trade in social labels) entre los Estados Unidos y Gran Bretaña (Hall et al. 2013, p. 31). En los Estados Unidos existía ya un antecedente transnacional del fenómeno del mugging, precisamente porque la crisis de condiciones económicas y sociales de los Estados de bienestar (aún con sus diferencias) empezaba a revelar su carácter global. Sin embargo, el análisis de los procesos de etiquetamiento revelaba el carácter profundo de la crisis: un proceso de naturalización de la diferencia, de atribución inflexible de características criminales a aquellos sujetos que no representaban el cuerpo íntegro de los valores tradiciones de las sociedades del primer mundo. Mugging no sólo fue una etiqueta nueva, con la que se pretendía explicar lo que en realidad se buscaba ocultar, sino que fue el término que permitía la fusión de las expresiones de ansiedad de una sociedad en transición.

No obstante, el estudio de Hall et al. (2013) incorpora un elemento que hasta el presente no se había considerado central en el análisis de la crisis: cómo la raza aparece conectada a la política. Esto destaca la particularidad, no sólo del aspecto económico de la coyuntura, sino del tipo de sociedad que experimentaba la transición. Hall no considera el racismo como el punto de partida de la explicación del comportamiento de la prensa, los juzgados y de la "opinión pública" hacia un sector especial de la población (particularmente la gente negra y la gente de color, y dentro de ella, especialmente los jóvenes), sino que, tomando el camino del análisis de los presupuestos sobre los que se funda la identidad cultural inglesa (su carácter respetuoso, bondadoso etc. - eso que se llama "englishness")

${ }^{13}$ En el original: "They [the labels] not only place and identify those events; they assign events to a context. Thereafter the use of the label is likely to mobilize this whole referential context [...]." (Hall et al. 2013, p. 23). 
puede demostrar cómo se integra el problema de la raza en lo político. De esto es de lo que se trata: la denuncia del racismo como punto de partida del análisis, no permitiría ver cómo la raza funciona como medio de explicación, comprensión y resolución de una crisis en una coyuntura específica. Hall et al. (2013) no llegan sólo a identificar el problema racial, sino cuáles son sus fuentes. No se trata de una patología particular presente en cada individuo, se trata del carácter que una formación social adquiere en una coyuntura específica.

Los jueces asumieron la tarea de "enviar un mensaje" a la sociedad sobre la dureza con la que serían tratados los mugglers y a la vez reprodujeron en sus sentencias el discurso sobre una sociedad fuera de control, de que es necesario atacar la "permisividad social" [social permisiveness] (Hall et al. 2013, p. 35-36), y asumen la tarea de administrar la ansiedad, de "resolver la crisis": ellos construyen una causa (i.e. the mugging) para poder entonces orientar la crisis en un sentido específico (el desarrollo del estado de excepción). El discurso de los jueces pretendió identificar "el origen" de la crisis con el propósito de resolverla, pero en esta operación existe un paso necesario: el paso de la ansiedad (provocada por el "pánico moral" que suscita el mugging) al paso de la concesión de una política de control sobre la libertad de las personas.

No obstante, siguiendo a Hall et al. (2013), se podría decir que tal concesión no se realiza en términos abstractos, sino en términos totalmente históricos: son precisamente aquellos que "ponen en peligro" la supuesta "identidad homogénea" del pueblo inglés los que deben ser vigilados. Es decir, tal concesión de libertad, tal estado de excepción implica el develamiento del carácter racialmente estructurado de las instituciones y organismos públicos de la sociedad. La seguridad consistirá entonces en proteger al "pueblo inglés" de la "gente endemoniada" (folks devils) (Hall et al. 2013, p. 159-163), en proteger a "los ingleses" de aquellos que no son "reservados" emocionalmente - no tienen una moralmente deseable "reserva emocional", cuyo estruendo opera como una perturbación, no solo para 
los ingleses de élite, sino para cualquier partícipe de la englishness (p. 155). La "seguridad", la demanda por "protección" avanzó en una línea racista.

Tal situación es la que se logra revelar en Policing the crisis. Si la única novedad del fenómeno mugging fue la aparición del término en sí mismo, esto se debe a la prehistoria de tal fenómeno: la identificación de perfiles y el encarcelamiento de jóvenes negros era un proceso que tenía un lugar (físico, con implicaciones materiales, sobre los cuerpos concretos) en la sociedad de inicios de 1970 (Hall et al. 2013, p. 54-55). Mugging permitió nombrar la manera en la que el poder "articuló" raza y política.

Esto supone que la manera de entender la crisis en Policing the crisis trasciende los análisis limitados de varios sectores de izquierda, que consideran como únicamente válidas las identificaciones de clase. En la sociedad inglesa de finales de 1960 e inicios de 1970, se daba una crisis de transición, el paso de una coyuntura (marcada por el proyecto del Estado de Bienestar) a otra (el surgimiento de las condiciones favorables para el neoliberalismo - para Hall, una de estas condiciones es la concesión que hacen los sujetos para la conformación de un estado de excepción).

La crisis de la identidad inglesa, como conjunto de elementos axiológicos fusionados coherentemente (Hall et al. 2013, p. 142-145) decantó en que cada evento de la cotidianidad estuviera conectado con la transformación económica-social (pasar de ser imperio a ser "una sociedad más" en Europa), y con el dejar de ser una sociedad blanca a ser una sociedad multicultural. La conexión de estas dos expresiones de la transición tiene lugar en el problema racial que subyace a fenómenos sociales "emergentes" (e.g. el mugging). No se trata de decir que el mugging es una pantomima, sino de señalarlo como trabajo discursivo, como un trabajo producido desde de la articulación de contradicciones de orden económico, social y cultural. La crisis desemboca en una sociedad precipitada hacia el racismo como única salida a la ansiedad causada por las mutaciones del capitalismo.

El análisis en Policing the crisis conecta con lo planteado en la sección anterior acerca del carácter gramsciano del trabajo de Hall. Su concentración en lo concreto y sus diferentes determinaciones se realiza a tal nivel teórico 
que permite la vuelta a la lectura de lo concreto con una comprensión mayor y, a la vez, permite ver más allá de la situación concreta. No cabe duda de una sensibilidad que va de Gramsci a Althusser en el texto y que queda expuesta en la centralidad del concepto de "coyuntura". De esta manera, se puede ver cómo Hall, Critcher, Jefferson, Clarke y Roberts (2013) ponen a funcionar el concepto de coyuntura, precisamente a través de la adición de las diferentes determinaciones de la situación analizada, el momento específico de una formación social en el que confluyen las contradicciones (culturales y de clase) con los antagonismos (políticos).

La significativa presencia del concepto de articulación para captar el trabajo que el poder judicial, el poder policial y el poder mediático realizan a nivel de la estructura social dice de la manera en que, en el período de crisis, la articulación existente de sensibilidades, expectativas, valores, tradiciones, empieza a ceder paso a otras formas de articulación. La sobredeterminación de una formación social, específica en sentido histórico, genera rupturas en la articulación significativa de un orden económico y social, produciendo la oscilación entre periodos de estabilidad y periodos de profunda conmoción.

Policing the crisis construye un argumento en torno a la crisis de hegemonía de la social democracia. Su base social, con su propio sentido común, empezó a ser puesta de lado debido a una acumulación de contradicciones (Hall et al., 2013). De este modo, los autores asumen, vía Gramsci, que las nociones asentadas acerca de la política empiezan a verse desplazadas por el problema material concreto, en el que las transformaciones económicas (entre 1945 y 1960) giran drásticamente del modelo de la seguridad social y la redistribución, hacia un modelo basado en el recorte de los salarios (Hall et al., 2013). Este movimiento económico constituye, pues, el contexto, la primera instancia, de la crisis política en la que concentrarán su análisis. El mugging es, al final, una nueva articulación de contradicciones raciales, económicas y políticas que emerge en un período de transición. 


\section{Análisis de la crisis (II): la producción del sentido común neoliberal}

El análisis que Hall realiza del gobierno de Margaret Thatcher en The toad in the garden: Thatcherism among the theorists (1988b), así como la serie de ensayos escritos entre 1978 y 1988 reunidos en The hard road to renewal. Thatcherism and the crisis of the left (1988a), plantean un análisis de las condiciones previas y del modelo que se instaura en Inglaterra a partir de 1979, que venía gestándose desde la crisis del Estado de Bienestar que Hall et al. (2013) habían planteado anteriormente.

Lo que permite a Hall analizar el fenómeno del Thatcherismo - y no "el gobierno de Margaret Thatcher" -, es que contempla a "Thatcher más allá de Thachter". Esto significa que Thatcher (the Prime Minister) es la expresión de una confluencia mayor de elementos que se encuentran instalados en el sentido común de la población y más allá del personaje o partido que gana las elecciones. Así, Thatcher es el sujeto que enuncia el discurso que sostiene una proyecto social y económico que, para instalarse, requiere desmontar el sentido común que había construido la social democracia desde la época de la posguerra.

De este modo, Hall identifica el poder político no únicamente como "tomar el Estado" sino en su conducción atada a la medida en que produce hegemonía. Tal operación implica lograr la conducción de los medios de comunicación (no haciéndolos parte de la propiedad de la fuerza política sino "determinando" sus contenidos), lograr que el trabajo intelectual responda al proyecto político-cultural, y lograr la administración de las instituciones de acuerdo a determinados fines políticos. Según Hall, a través de estos medios, y no exclusivamente de ellos, se construyó un proyecto hegemónico al que se puede denominar Thatcherismo, pues no sólo dependió de la voluntad de Thatcher sino del restablecimiento de la "correlación de fuerzas" entre lo que Thatcher representa y el sentido común que había construido la socialdemocracia. 
Si el Thatcherismo logró ser una fuerza transformadora, es porque en su discurso se manifestaron al menos dos elementos claros: (i) la lectura de la crisis de hegemonía que tenía la social democracia y que, en buena medida, se debía a la crisis económica ocasionada por el término de un ciclo de crecimiento económico, y (ii) la capacidad de apropiarse del discurso de la izquierda para utilizarlo como justificativa del proyecto neoliberal y neo-imperialista. Esto último, que podríamos denominar la "usurpación simbólica de la izquierda" forma parte de la estrategia de instauración de un nuevo sentido común, esta vez neoliberal, que logra la combinación de elementos arraigados en el imaginario de la población inglesa (familia, deber, honor) con la "renovación" que proponía el neoliberalismo.

La renovación propuesta por el neoliberalismo de Thatcher giraba en torno a la idea de libertad. Se trata de una idea de libertad (entendida como la no intromisión del Estado en la vida de los ciudadanos) que se opone a la igualdad (como algo que se puede conseguir a través de las políticas sociales). No obstante, para Hall, el Thatcherismo encuentra también un fundamento en el "lado inconsciente" de la sociedad inglesa, un aspecto reprimido pero que sale a la luz cuando se ve representado a sí mismo en el discurso del otro: la necesidad de castigarse a sí mismo por el bienestar que se ha proporcionado. Esto que Hall llama, creo que metafóricamente, el "masoquismo" (Hall, 1988a, p. 166) de la sociedad inglesa, constituye pues una contradicción. El éxito de Thatcher está en sintetizar esa contradicción, ese nivel subjetivo de la crisis, desde la promoción de un determinado tipo de sujeto: el sujeto de la libertad concedida por el "nuevo proyecto neoliberal".

No significa entonces que exista efectivamente un inconsciente colectivo sino que precisamente, lo que logra Thatcher es encausar la voluntad colectiva hacia su proyecto (o el proyecto político que ella representa). De tal manera que, la voluntad colectiva sólo puede conformarse en los marcos de este proyecto. Si existe algún disenso, se hará también dentro de estos marcos. Así, su hegemonía no consistió en anular las expresiones sociales que no se enmarcan en el proyecto neoliberal, sino que todo proceso de 
voluntad colectiva se hiciera en los términos de la hegemonía, es decir, dentro del sentido común neoliberal.

Para Hall, Thatcher puso en marcha un razonamiento que la izquierda británica no fue capaz de emprender. Aquel razonamiento que asume que la hegemonía del neoliberalismo se consolida en el plano de la subjetividad, que la hegemonía no consiste en la manipulación de la verdad (o de la realidad, o de los sujetos) sino en su producción.

En la particular coyuntura de la sociedad inglesa, Thatcher logró aprovechar la situación geopolítica para agregar determinaciones a su particular contexto: manejar un discurso provisto de términos de izquierda en la disputa por las islas pertenecientes al mar territorial argentino (las Islas Malvinas) (Hall, 1988a). Thatcher logra ejercer un gobierno a favor de la autoridad de los mercados y a la vez contar con el respaldo popular construyendo un discurso que aglutine diversos sectores de la sociedad inglesa con un mismo mensaje que integró el sentido colonialista de esa sociedad, con los contenidos de la lucha de la izquierda. Dice Hall (1988a, p. 72):

el Thatcherismo ha literalmente robado de la boca [de la izquierda] los eslóganes de autodeterminación nacional y antifascismo. La soberanía del pueblo, el derecho a la autodeterminación, la debilidad de los dictadores, la maldad de las juntas militares, la antorcha de la libertad, el gobierno de la ley internacional y la cruzada antifascista: en una espantosa pero conveniente ventriloquía, éstos han sido elevados en el asta de la derecha ${ }^{14}$

Los insights gramscianos de Thatcher tienen que ver con su capacidad para responder a la decepción real de las personas en la práctica cotidiana de "enfrentarse" al Estado (a su lógica burocrática, a sus políticas de impuestos), construyendo un antagonismo entre "El Estado" y "la gente".

\footnotetext{
${ }^{14}$ En el original: "Thatcherism has literally stolen the slogans of national self-determination and anti-fascism out of mouths. The sovereignty of people, the right of self-determination, the wickedness of dictators, the evil of military juntas, the torch of liberty, the rule of international law and the anti-fascist crusade: in a hideous but convenient ventriloquism, they have been run up the flagpole of the right." (Hall, 1988a, p. 72).
} 
Esta lógica del "ellos" (El Estado) vs. "nosotros" (el pueblo inglés) es pues una construcción discursiva. Hall, siguiendo a Laclau (1977), coincide en que el "pueblo" como tal no existe, sino que se construye precisamente a través de la articulación de diferentes lógicas discursivas "en" y "a través de" diferentes prácticas de clase (Hall, 1988a). Entonces, tal articulación no responde exclusivamente a demandas económicas, sino que emergen del bagaje de ideas en las que las cosmovisiones, tradiciones y valores se han consolidado en el propio proceso de construcción de una identidad. En el caso de Thatcher, Hall adoptará el término "populismo autoritario" para nombrar "las maneras en las que el campo de la moralidad popular ha sido rearticulado en un periodo de crisis alrededor de temas tales como el crimen, disciplina y orden social" (Hall, 1988a, p. 138).

El desarrollo de una lectura gramsciana del Thatcherismo no se da porque ésta fuera la única vía posible para comprenderlo sino porque, en su análisis, demuestra las limitaciones del análisis tradicional de la izquierda que, por reposar en la esperanza de la configuración de la "última instancia" del desarrollo histórico, no puede considerar cómo opera la situación concreta en la cual lo económico interactúa con todo tipo de factores. A la vez, el análisis gramsciano de Hall permite mantener dentro del marxismo su potencial metódico para el análisis de las transformaciones sociales, en Inglaterra y más allá.

\section{Conclusión: comprender la crisis}

Policing the crisis tiene el valor de ayudar a analizar aquello que inicialmente aparece como invisible: las conexiones profundas entre la cultura y la economía, entre la política y la diferencia racial. Tal como hicieron los autores al develar que la institución policial había trabajado ya con presupuestos de naturalización entre condición racial y crimen (antes de que apareciera el mugging como etiqueta), el análisis de la coyuntura implica siempre integrar el análisis del pre-texto (como aquello que está antes del texto, de la etiqueta, de "la solución a la crisis"). No es posible 
un fenómeno (e.g. el pánico moral) sin las experiencias pre-discursivas que ligan en sentido económico y político a los distintos actores que integran el orden social. De aquí que un análisis en la línea de Policing the crisis consista en analizar cómo se construye la ruptural unity que fusiona contradicciones y antagonismo. Tal ruptural unity se expresa en el repertorio compartido por distintos poderes legitimados con aquellos sujetos que experimentan cotidianamente la desestabilización de todos sus supuestos.

Desde el análisis del Thatcherismo se concluye que, en el capitalismo neoliberal, ningún proyecto político se puede sostener únicamente a partir de una base económica, sino que requiere ser un proyecto cultural. Así, este análisis de la coyuntura exige a la izquierda una renovación de su lenguaje, asumiendo la lucha en el plano de producción de ideas que articulen los valores existentes a proyectos políticos "donde podamos comenzar la disputa histórica sobre lo que un nuevo tipo de civilización debe ser" (Hall, 1988a, p. 173). ${ }^{15}$ Esto implica también, alejarse del discurso nostálgico (lo inmediato anterior es pues la social democracia - que, para Hall, es una cara más amable del capitalismo), y proporcionar vías de identificación de la población, en la cual libertad e igualdad se comprendan en el marco de justicia.

Esto es quizá lo que Jordan T. Camp (2016) confronta en Incarcerating the crisis. Freedom struggles and the rise of the neoliberal State. Si bien en el siglo XXI "la retórica 'ciega al color' [color-blind rethoric] de la seguridad, la ley, y el orden ha sido efectiva generando el consenso para el despliegue de soluciones carcelarias ante las crisis de hegemonía del estado neoliberal" (Camp, 2016, p. 11), ${ }^{16}$ es también importante, reconocer los procesos de resistencia desde abajo que se ligan a la tradición de movimientos de liberación y que impiden cerrar el círculo de la totalidad de la dominación.

${ }^{15}$ En el original: "[...] where we can begin the historic quarrel about what a new kind of civilisation must be." (Hall, 1988a, p. 173).

${ }^{16}$ En el original: "the color-blind rhetoric of security, law, and order has been effective in winning consent to the neoliberal state's deployment of carceral resolutions of crises of hegemony." (Camp, 2016, p. 11). 
Los movimientos de izquierda no pueden reposar en la "ilusión del intelectual", esperando que "surja" la conciencia como resultado de la agudización espontánea de las contradicciones. Por el contrario, el pueblo debe ser construido en la articulación de un nuevo sentido común. Si Thatcher logró producir "unidad en la diversidad" es porque sus ideas lograron permear las instituciones y también la sociedad civil. La izquierda tendrá que recuperar sus términos, pero llenándolos de nuevos significados y tendrá también que generar una nueva poética de la transformación.

Jorge Daniel Vásquez es Doctor en Educación y $\mathrm{PhD}(\mathrm{c})$ en Sociología (Universidad de Massachusetts). Profesor Titular en la Pontificia Universidad Católica del Ecuador.

$\triangle$ jdvasquez@umass.edu

\section{Referencias}

1. ALTHUSSER, Louis. For Marx. Londres: Verso, [1965] 2005.

2. CAMP, Jordan T. Incarcerating the crisis. Freedom struggles and the rise of the neoliberal State. Oakland: University of California Press, 2016.

3. ENGELS, Frederick. Engels to Joseph Bloch. 21-22 September. In: Karl Marx and Frederick Engels: Collected works 49. Nueva York: International Publishers, [1890] 2002. p. 33-35.

4. GRAMSCI, Antonio. Selections from the prison notebooks. Nueva York: International Publishers, 1971.

5. HALL, Stuart. Cultural studies 1983: a theoretical history. Durham: Duke University Press, [1983] 2016.

6. HALL, Stuart. Gramsci's relevance for the study of race and ethnicity. In: MORLEY, David; CHEN, Kuan-Hsing (eds.). Stuart Hall. Critical dialogues in cultural studies. Londres: Routledge, [1986] 1996a. p. 411-439.

7. HALL, Stuart. The problem of ideology: Marxism without guarantees. In: MORLEY, David; CHEN, Kuan-Hsing (eds.). Stuart Hall. Critical dialogues in cultural studies. Londres: Routledge, [1985] 1996b. p. 25-46.

8. HALL, Stuart. The hard road to renewal. Thatcherism and the crisis of left. Londres: Verso, 1988a. 
9. HALL, Stuart. The toad in the garden: Thatcherism among the theorists. In: NELSON, Cary; GROSSBERG, Lawrence (eds.). Marxism and the interpretation of culture. Urbana and Chicaco: University of Illinois Press, 1988b. p. 35-73.

10. HALL, Stuart. Signification, representation, ideology: Althusser and the poststructuralist debates. Critical Studies in Mass Communication, v. 2, p. 91-114, 1985.

11. HALL, Stuart. Re-thinking the 'base and superstructure' metaphor. In: BLOOMFIELD, Jon (ed.). Class, hegemony and party. Londres: Lawrence \& Wishart., 1977. p. 43-72.

12. HALL, Stuart; CRITCHER, Chas; JEFFERSON, Tony; CLARKE, John; ROBERTS, Brian. Policing the crisis. Mugging, the State and law \& order. Londres: Palgrave Macmillan, [1978] 2013.

13. HALL, Stuart; JEFFERSON, Tony. Resistance through rituals. Youth subcultures in post-war Britain. Londres: Routledge, 1976.

14. JHALLY, Sut. Stuart Hall: the last interview. Cultural Studies v. 30, n. 2, p. 332345, 2016. doi: 10.1080/09502386.2015.1089918

15. LACLAU, Ernesto. Politics and ideology in Marxist theory. Londres: Verso, 1977.

16. MARX, Karl; ENGELS, Friedrich. The German ideology. Londres: Lawrence \& Wishart, [1845] 1970.

17. MARX, Karl. El dieciocho brumario de Luis Bonaparte. In: C. Marx/F. Engels, obras escogidas, Moscú: Editorial Progreso, [1852] 1969. p. 97-185.

18. MARX, Karl. El Capital. Crítica de la economía política. v. I. México: FCE, [1867]1946.

19. MELLINO, Miguel. Apuntes sobre el método de Stuart Hall. Althusser, Gramsci y la cuestión de la raza. Revista de Estudios Sociales v. 64, p. 89-105, 2018. doi: 10.7440/res64.2018.07

Recibido: 17 feb. 2020 Aprobado: 27 mayo 2020 